\title{
Exploring biodiversity mental constructs of urban residents in an emerging South-East Asian country
}

\author{
Minh-Hoang Nguyen 1,2,*
}

Thomas E. Jones ${ }^{1}$

${ }^{1}$ Graduate School of Asia Pacific Studies, Ritsumeikan Asia Pacific University, Beppu, Oita 874-8577, Japan

${ }^{2}$ Centre for Interdisciplinary Social Research, Phenikaa University, Yen Nghia Ward, Ha Dong District, Hanoi 100803, Vietnam

*Correspondence: ng19m6tk@apu.ac.jp (M.-H.N)

\begin{abstract}
Biodiversity loss is occurring at unprecedented rate. Understanding the mental constructs of the public can help implement more effective programs and regulations for decelerating the loss. Although many studies have been conducted to study the biodiversity mental constructs of the public, little is known about those of urban residents in an Asian emerging country, like Vietnam. Employing the Grounded Theory and semi-structured interviews, the current study attempts to explore three biodiversity perceptions of urban residents in two Vietnamese largest cities: i) biodiversity and biodiversity loss, ii) impacts of biodiversity and biodiversity loss on human, and iii) human's reaction towards biodiversity and biodiversity loss. Besides identifying important conceptual dimensions, we also find the influence of cultural value, the awareness of multistakeholders' participation, and some misunderstandings in the urban residents' perceptions. Thus, we recommend policymakers to promote education and public communication of biodiversity-related knowledge, as well as multistakeholders' cooperation for achieving the $11^{\text {th }}$ cultural progressive value - the environmental-healing element.
\end{abstract}

\section{Introduction}

During the last several decades, biodiversity loss has happened at an unprecedented rate despite the endeavors made by multiple governments, institutes, and people. The World Wildlife Fund (WWF)'s Living Planet Report 2020 shows a catastrophic decline of $68 \%$ in the numbers of mammals, birds, fishes, plants from 1970 to 2016 [1]. Besides the statistics from WWF, the Intergovernmental Science-Policy Platform on Biodiversity and Ecosystem Services [2] also reports that around 1 million species are threatened with extinction, but current global responses are not sufficient. The global biodiversity loss is attributable to various reasons, such as climate change, deforestation, invasive species, land-use intensification, population and economic growth, and wildlife trade [3-6]. Public participation is usually considered pivotal for biodiversity conservation, protected area management, and policy-making [7-10].

As conservation effectiveness can be improved by taking into account residents' perceptions and knowledge, it is essential to understand the public's perceptions towards biodiversity conservation and management. Several previous studies have examined the public views and knowledge 
regarding biodiversity and biodiversity-related issues. Those studies can be classified into two types. The first type attempts to quantify individuals' knowledge and perceptions through established scales [8,11], whereas the second type aims to explore individuals' perceptions through conceptual constructs (or mental constructs) $[9,10]$. The current study belongs to the second type, which aims to examine the perceptions towards biodiversity and biodiversity loss of Vietnamese urban residents through their mental constructs. In the following sub-sections, we would 1) provide a brief literature review on qualitative studies regarding peoples' perceptions about biodiversity, 2) explain why understanding urban residents' perceptions is crucial for biodiversity conservation, and eventually 3 ) address the study's research questions and structure.

\subsection{Biodiversity: complexity in both definition and mental construct}

The definition of biodiversity is myriad. According to the Stanford Encyclopedia of Philosophy [12], the term "biodiversity", which was heralded by a symposium in 1986 and a follow-up book Biodiversity [13], is a short form of "biological diversity" or "biotic diversity". The two most inclusive and widely used definitions might be the definitions employed by the Parties to the Convention on Biological Diversity (CBD) and IPBES. Both definitions explicitly emphasize the variability feature of biodiversity. Mace, et al. [14] recommend using the Convention on Biological Diversity [15]'s definition due to its common usage, policy status, and inclusiveness: "the variability among living organisms from all sources including, inter alia, terrestrial, marine and other aquatic ecosystems and the ecological complexes of which they are part; this includes diversity within species, between species and of ecosystems".

Biodiversity's definition is multiplex, especially when putting it in an ecological system. Sometimes, the terms biodiversity and ecosystem service are even used interchangeably. Thus, in order to reduce the confusion between the two terms (biodiversity and ecosystem services) and improve biodiversity conservation's effectiveness, Mace, Norris and Fitter [14] propose three categories for classifying biodiversity: i) biodiversity as a good, ii) biodiversity as a final ecosystem service, and iii) biodiversity as a regulator of ecosystem processes. The classification has later become foundational categories for studying and interpreting issues related to biodiversity and ecological system.

Like the definition, residents' mental constructs regarding biodiversity are also complex and varying according to the individuals' normative aspects. Here, we employ the term 'mental constructs' referring to the study of Fischer and Young [9], which indicates a set of complex constructs that may include i) specific terms that demonstrate a concept, ii) definitions of a concept, and iii) prototypical images that encapsulate typical examples for representativeness of the concept. In their study, Fischer and Young find that the public in a Scotland's national park obtains rich mental notions of biodiversity, regardless of their scientific knowledge.

Various other studies also advocate that lay persons can acquire rich and deep perceptions towards biodiversity in spite of their limited scientific knowledge about the terms [16-19]. Scientists find that heterogeneity, naturalness, peacefulness, richness, and wilderness are primary attributes that are usually attached to the biodiversity concept [9,10,20]. Muratet, et al. [21] reveals that "plant species richness is mainly appreciated for the beauty and sense of well-being it provides", while a study on farmers' perceptions towards biodiversity find that spirituality and emotions are also 
linked to biodiversity [22]. Besides these notions, the general public also associates biodiversity with the natural balance, food chains, and the interactions between humans and nature [9].

Not only do scientists attempt to explore the normative attributes of biodiversity in lay persons' perceptions, but they also utilize scientific definition's classification to categorize the mental constructs. For example, the biodiversity's classification proposed by Mace, Norris and Fitter [14] is also employed in interpreting the mental constructs of the public about biodiversity by Bakhtiari, Jacobsen, Strange and Helles [10]. Particularly, using the qualitative data acquired from interviews and focus group discussions with local laypeople, they categorize individuals' perceptions about forest biodiversity as i) a good in itself and ii) regulator of the ecosystem.

In general, several studies have been conducted to explore the mental constructs of the general public regarding biodiversity. However, those studies are mainly about the residents living near a forest or protected area. Even though Muratet, Pellegrini, Dufour, Arrif and Chiron [21]'s study was conducted among urban park users, its scope is not particularly about biodiversity, but plant species richness. Most of the studies were in developed Western countries, so little is known about the public's perceptions in other countries, especially those with different cultural values [23-25] and economic conditions [26]. Thus, exploring the perceptions of biodiversity (loss) among urban residents in Vietnam is our main objective. The next sub-section will explain the importance of understanding urban residents's perceptions of biodiversity (loss).

\subsection{Why is understanding urban residents's perception of biodiversity important?}

Several reasons direct the current study to explore urban residents' mental construct of biodiversity (loss). One of those is the rising urban markets' demand for wildlife products. Wildlife trading is a major threat to biodiversity conservation. It is recorded that more than $24 \%$ of terrestrial bird, mammal, amphibian, and squamate reptile species are traded globally, and around 4,064 more species is predicted to be included in the future wildlife trading system [27]. The illegal wildlife trade has driven many species toward extinction. For example, the last Javan rhino in Vietnam, the research location, was found dead with its horn hacked off in 2010. Due to poaching activities, other species, like bear, pangolin, tiger, etc., are threatened with extinction in Vietnam [28]. Indeed, Vietnam Red List reported an increase of 161 threatened and endangered species (animals and plants) from 1996 to 2007 [29].

Reasons for the existence of the illegal wildlife trade, one of the world's largest illegitimate businesses, are myriad [30]. Wildlife is primarily traded for medicines, luxury goods, cultural purposes, and petting [27]. Despite multiple policies and regulations implemented, wildlife trading intensity for these products is still rising. Illegal trading's continuous expansion is largely attributable to the growing price and demand for wildlife products and utilities in urban markets [31,32]. Thus, understanding the mental constructs of urban residents about biodiversity (loss) might ease the policy-making and prevention programs that cut down wildlife consumption demand in urban areas.

Exploring urban residents's mental constructs might also provide valuable information for policymaking and management in another aspect of biodiversity conservation: nature-based recreation. Among multiple benefits provided by biodiversity, improving human's health and well-being 
through the cultural pathways is one of the most valuable merits [33]. By interacting with nature or immersing in a natural environment, humans might have lower risks of mental illness and increased happiness. Such merits of biodiversity might lead to the increasing demand for naturebased recreation in protected areas globally, which might, in turn, generate sustainable finance for biodiversity conservation [34-36]. Specifically, Khai and Yabe [37] find that urban residents in the Mekong Delta are willing to pay approximately $\$ 11$ million per year for biodiversity conservation. However, the ideal interaction between tourism and biodiversity conservation can only be obtained with appropriate management and regulation strategies [35]. Given that a great part of naturebased tourism's demand derives from urban areas [38-40], it is reasonable to examine the future visitors' perceptions towards biodiversity (loss) for better monitoring, management, and regulation in protected areas.

Besides protected areas, urban parks are also ideal places for satisfying city dwellers' demand for nature-based recreation. Urban parks which are cohabitation grounds between residents and nature are expected to reduce the detrimental impacts of urbanization and improve residents' well-being. The species richness of plants and birds in urban greenspaces is positively correlated with the visitors' psychological benefits [41,42]. However, it is also found that urban residents do not notice the biodiversity in greenspaces despite their strong preference towards a rich diversity of species (excluding insects) and its positive association with their well-being [43]. Due to this contrary in the human-biodiversity interaction, understanding the mental constructs of urban residents regarding biodiversity is vital for aiding future general public conservation initiatives and policies.

\subsection{Research objectives}

Due to the lack of studies regarding biodiversity perceptions in developing countries and the necessity of understanding urban residents mental constructs, the current study attempted to answer three research questions:

1. What are the Vietnamese urban residents' perceptions regarding biodiversity and biodiversity loss?

2. What are the Vietnamese urban residents' perceptions regarding biodiversity and biodiversity loss impacts on humans?

3. What are the Vietnamese urban residents' perceptions regarding humans' measures to conserve biodiversity and halt biodiversity loss?

\section{Methodology}

In the current study, we employed the Grounded Theory methodology to explore Vietnamese mental constructs about biodiversity and biodiversity loss. Grounded Theory is a well-known methodology in many psychological and social sciences [44]. The methodology was initially employed in Awareness of Dying by Glaser and Strauss [45], the founders of Grounded Theory [46]. Grounded Theory is usually used to study phenomena with little prior knowledge or information. This is also the main reason we employed the Grounded Theory in this study. Even though several studies have been done to explore the mental constructs of layresidents in Western countries [9,10], little is known about those of urban residents in emerging South-East Asian countries with rich biological resources, like Vietnam. As the mindset and perceptions of an individual is constructed and continuously reinforced by the surrounding environment (e.g. 
economic, socio-cultural, and environmental values) [23-25], there are three reasons that make using Grounded Theory plausible in the current study: 1) the current study's site is in a developing country, whereas the former studies' sites are in developed countries 2) the current study's samples obtain different culture with the former studies' (East Asian culture versus Western culture); and 3) the current study's samples are living in urban environment, whereas the the former studies' samples are tourists or living near natural environment.

Since the separation of Glaser and Strauss due to divergent viewpoints, there have many variations of how to use Grounded Theory [47], namely: post-positivism approach of Glaser and Strauss, symbolic interactionism and pragmatism approach of Strauss and Corbin, constructivism approach of Charmaz, etc. In brief, Grounded Theory is "a dynamic methodology in that it is characterized by the contemporaneously interpreted philosophical perspectives of the researcher in response to their interaction with wider social forces" [47]. Despite the methodological dynamism of Grounded Theory, Chun Tie, Birks and Francis [44] suggest a general research design framework with six primary steps: 1) purposive sampling, 2) data collection, 3) initial coding, 4) intermediate coding, 5) advanced coding or grounded theory. In follow, we will present how the current study was conducted according to these steps.

\subsection{Data sampling and collection}

The current study is about the mental constructs of Vietnamese urban residents towards biodiversity and biodiversity loss, so we purposively collected data from the two largest cities in Vietnam: Ho Chi Minh city and Hanoi capital city, respectively. Ho Chi Minh is located in the South of Vietnam with approximately 9 million residents, while Hanoi capital city is located in the North of Vietnam with more than 8 million residents [48]. While the former is considered the largest financial center, the latter is deemed the cultural and political center of Vietnam. By collecting data from these two regions, we expected to mitigate the economic, social, and cultural biases due to geographical distinction.

For collecting the data, we conducted face-to-face semi-structured interviews. Because biodiversity is a multiplex and quite scientific issue, it is a huge barrier to get relevant answers from layresidents. It is even more challenging when the interviewees are urban residents who have little experience with natural environments during their lifetime. Thus, a structured interview could not provide enough flexibility to achieve satisfactory answers. On the opposite, the unstructured interview is relatively varying and incomparable among cases, so it is not a suitable method to examine the mental constructs of biodiversity, which requires a systematic evaluation and comparison between individuals. As a result, we chose the semi-structured interview because it shares the advantages of both structured and unstructured interviews: organized, systematic, and highly flexible [49,50].

The interview questions were designed by referring to previous studies $[9,10]$. Nevertheless, they were modified to fit with the current study's research questions. Two pilot interviews were also conducted before finalizing the final version of the interview guideline. The interview guideline with two major sections is presented in Figure 1. The first section explores the interviewee's mental constructs about biodiversity, whereas the latter explores the biodiversity loss aspect. 


\begin{tabular}{|c|c|}
\hline \multicolumn{2}{|c|}{ I. Biodiversity } \\
\hline 1 & $\begin{array}{l}\text { Have you ever come across the term "biodiversity", or biological diversity? } \\
\text { If not, provide information: "Biodiversity means the variety of life. Biodiversity } \\
\text { includes all living things and the environment of which they are part." }\end{array}$ \\
\hline 2 & $\begin{array}{l}\text { What does 'biological diversity' mean to you? What first comes to your mind? } \\
\text { Anything else? }\end{array}$ \\
\hline 3 & $\begin{array}{l}\text { How important is biological diversity to human beings? And why? } \\
\text { How important is biological diversity to your everyday life? And why? }\end{array}$ \\
\hline 4 & $\begin{array}{l}\text { In your opinion, in what way biological diversity could best be managed and } \\
\text { maintained? }\end{array}$ \\
\hline \multicolumn{2}{|r|}{ II. Biodiversity loss } \\
\hline 1 & $\begin{array}{l}\text { Have you ever come across the term "biodiversity loss"? } \\
\text { If not, provide information: "Biodiversity loss is a decrease in biodiversity within a } \\
\text { species, an ecosystem, a given geographic area, or Earth as a whole." }\end{array}$ \\
\hline 2 & $\begin{array}{l}\text { What does 'biodiversity loss' mean to you? } \\
\text { What first comes to your mind? }\end{array}$ \\
\hline 3 & $\begin{array}{l}\text { How does biodiversity loss affect human beings? } \\
\text { How does biodiversity loss affect your everyday life? }\end{array}$ \\
\hline 4 & How do you think biodiversity loss could best be halted? \\
\hline 5 & $\begin{array}{l}\text { Do you think the people around you and yourself can contribute to the management } \\
\text { and conservation of biodiversity or stopping biodiversity loss? }\end{array}$ \\
\hline
\end{tabular}

Figure 1: The interview guideline which is implemented accordingly.

All the semi-structured interviews were conducted from $15^{\text {th }}$ November 2020 to $26^{\text {th }}$ December 2020 in both Ho Chi Minh and Hanoi cities. We selectively chose interviewees through our social 
network. When the requested residents agreed to participate in the interview, the interview time and location were determined for the convenience of interviewees. Before any interview, the permission of recording the interview was asked. Then, the content and purpose of the interview were thoroughly explained, along with the guarantee of the participants' confidentiality. The interview only started when the interviewee verbally consented to participate in the interview, which was recorded. There was no required number of participants, but we applied the 'theoretical saturation' principle to decide when to stop the interview process [51]. Eventually, we acquired 38 recorded responses, of which 22 were in Ho Chi Minh city, and the remaining 16 were in Hanoi city. The average length of an interview was about 30 minutes.

The sample was purposively selected to reflect a range of residents from different age cohorts, genders, occupations, and prior experiences that might have dissimilar mental constructs. Therefore, we tried to diversify the attributes of the interviewee as much as possible. Eventually, 38 interviewed residents were distributed across all age cohorts: $39.47 \%$ from $18-30,31.58 \%$ from 31-55, and 28.95\% from above 55 (see Figure 2-A). For gender, 63.16\% of samples are female, and the remaining $36.84 \%$ are male (see Figure 2-B). We also selected residents from a wide range of occupations, such as banker, engineer, entrepreneur, freelancer, government officer, housewife, manager, media producer, teacher, etc. Twenty-four interviewed residents $(63.16 \%)$ reported that they have ever lived near a jungle or a coastline.

A

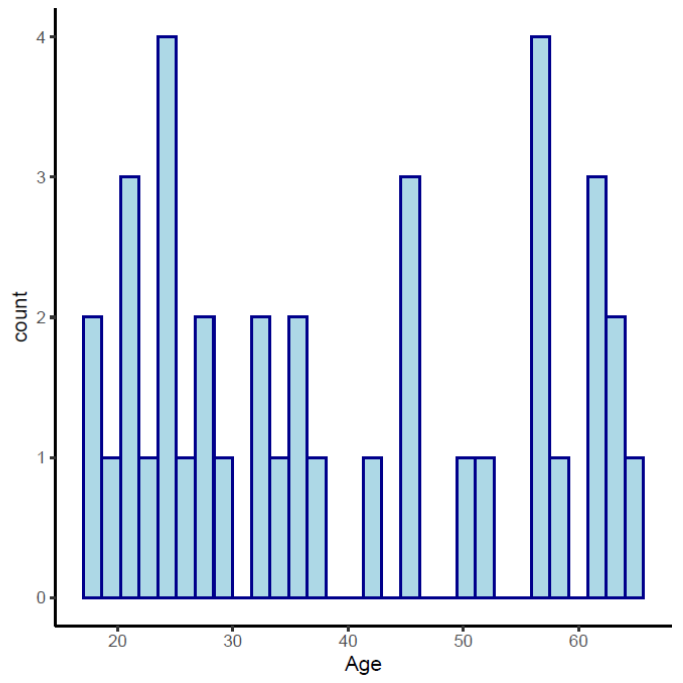

B

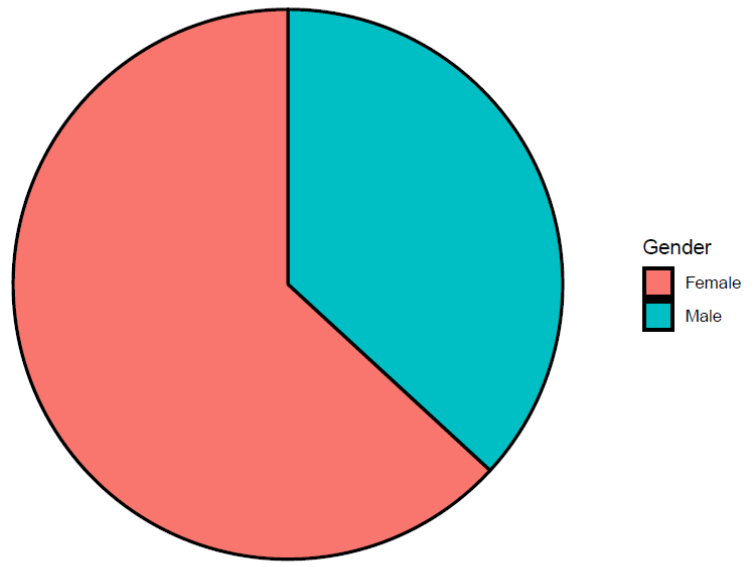

Figure 2: The distribution of interviewed samples by: $\mathbf{A}$ - age, and $\mathbf{B}$ - gender

\subsection{Data coding}

Alike other studies employing Grounded Theory, we performed three-step coding after the data collection process: initial coding, intermediate coding, and advanced coding. As all the interviews were conducted in Vietnamese, the transcribed texts from the recordings were later translated into English. Whenever we think the translation is not accurate, back and forth translations were performed multiple times until we reached the "correct" interpretation of the interviewees' viewpoint [52]. It took more than two weeks to complete the transcription and translation (between $8^{\text {th }}$ January and $25^{\text {th }}$ January 2021). 
In initial coding, we inductively create as many meaningful codes as possible by reading the transcribed texts line-by-line. In other Grounded Theory studies, the coding usually has only three types of code - action, interaction, and process, which are eventually combined to generate a complete diagram or hypotheses [51]. For example, the actions can be as follows: 'the air is clean', 'the forest is green', 'the animal becomes extinct'; the interactions can be as follows: 'biodiversity helps balance the ecosystem', 'biodiversity loss breaks the biological life cycle'. We defined the process as a complicated set of actions and interactions that was hard to be separated. The process can be as follows: 'biodiversity and biodiversity loss affect the variety of agricultural products that I consume every day'.

The next step is called intermediate coding. By continuously comparing the action, interaction, and process codes, we tried to find the general categories for codes that have similar characteristics or patterns. The comparison process was repeated multiple times until we considered the categories as most coherent, comprehensive, and fit with the codes. This was also the process when we decided whether the data were theoretically saturated or not. Specifically, if no new category emerges from the last four interviewees' responses (two in Hanoi city and two in Ho Chi Minh city), the theoretical saturation can be deemed to be reached. In fact, we reached theoretical saturation after the first group of interviewees (38 residents), so no further interview was required.

The last step is advanced coding. Birks and Mills [53] defined advanced coding as "techniques used to facilitate the integration of the final grounded theory". In other words, advanced coding is employed to generate the final theory or most integrated category. This theory might be abstract and represent many issues [44]. In the next section, we would present the most integrated categories (or grounded theories) within the mental constructs of biodiversity and biodiversity loss, along with their statistics and typical responses of interviewees.

\section{Results}

\subsection{Perceptions about biodiversity (loss)}

Out of 38 respondents, $36.84 \%$ reported that they have never heard of biodiversity, and that percentage for biodiversity loss is $52.63 \%$. Based on their responses, we categorized their perceptions into three perceptions and five features. The perception is the respondents' impression about the term 'biodiversity' and 'biodiversity loss', whereas the feature is the characteristics that they relate to 'biodiversity' and 'biodiversity loss'.

Overall, three Vietnamese urban residents' perceptions of biodiversity were found: 1) goods in an ecosystem, 2) an ecosystem itself, and 3) a stage of equilibrium. In contrast, biodiversity loss perceptions were also categorized as 1) the loss of goods in an ecosystem, 2) the loss of an ecosystem itself, and 3) the loss of the stage of equilibrium, respectively. The first two perceptions were referred to the definitions proposed by Bakhtiari, Jacobsen, Strange and Helles [10] and Mace, Norris and Fitter [14]. However, there was a certain difference. While the respondents in our study perceive biodiversity as an ecosystem, respondents in Bakhtiari, Jacobsen, Strange and Helles [10]'s study think biodiversity is a regulator of the ecosystem.

One example of how an interviewee perceived biodiversity as goods in an ecosystem is presented as follows: 
"Basically, I think biodiversity is something that is closely connected to nature. There are trees, and the environment is clean. Humans, plants, and other animals live peacefully together."

Interviewee 36 (65 years old, male, retiree, Ho Chi Minh)

On the contrary, biodiversity loss is perceived as the loss of goods in an ecosystem:

"To what I know, biodiversity loss is the extinction of some species because humans destroy the natural environment of those species. The population of plants and animals also decline, accordingly."

Interviewee 28 (35 years old, female, banker, Ho Chi Minh)

Below responses belong to the interviewees who thought biodiversity is an ecosystem itself,

"To what I understand, biodiversity is a natural ecosystem that encompasses many things, such as forest, trees, flowers, water, wild animals, etc. There are also rare soil or stones in the ecosystem."

Interviewee 9 (24 years old, female, officer, Hanoi)

and biodiversity loss is the loss of an ecosystem itself:

"Biodiversity is associated with the living environment, so when the diversity is lost, the environment will be gradually modified, deteriorated, and become disappear."

Interviewee 14 (22 years old, female, student, Hanoi)

For a few numbers of Vietnamese urban residents, biodiversity is neither what the scientists define nor their counterparts in the southern region of Scania perceive. They think biodiversity represents a stage of equilibrium. That stage of equilibrium is expressed through the harmony and balance in their imagination of biodiversity.

"I think biodiversity has several matters. First, forest, mountain, nature, plants, sceneries, living environment have to be harmonious with the human's life [...]"

Interviewee 24 (62 years old, male, officer, Ho Chi Minh)

"Biodiversity is a balance between species, in which species mutually negates each other. If the number of one species in the environment declines, the natural balance 
will be lost, so we must keep all animals and plants at a balance stage. Such balance will create harmony."

Interviewee 30 (38 years old, female, teacher, Ho Chi Minh)

While only a few respondents perceived biodiversity as a stage of equilibrium, most of them (34.21\%) viewed biodiversity loss as the loss of the stage of equilibrium.

"I've heard about biodiversity. For example, the human focuses on planting or nurturing certain species, so they exterminate other species, creating a natural imbalance."

Interviewee 30 (38 years old, female, teacher, Ho Chi Minh)

"Biodiversity loss is the unbalance number of species in the nature and number of individuals in a population, causing the environmental disorder."

Interviewee 2 (21 years old, female, student, Hanoi)

When talking about biodiversity, the respondents connected their perceptions of biodiversity with five primary features: 1) high diversity, 2) plentifulness, 3) cleanliness and refreshment, 4) naturalness, and 5) existence of unique objects/species. The most usually mentioned feature $(44.74 \%)$ is the genuine meaning of the term 'biodiversity': high diversity. Mace (2007) also found this dimension in their study about the biodiversity mental construct of individuals in a national park. A student in Hanoi related biodiversity with high diversity and plentifulness as follows:

"In my opinion, the term 'biodiversity' indicates the diversity, uniqueness, and plentifulness of plants and animals in the environment."

Interviewee 10 (21 years old, female, student, Hanoi)

Interestingly, the respondents could report the features of biodiversity loss more frequently than biodiversity (see the percentage in Table 1). The five primary features attached to biodiversity loss were: 1) extinction, 2) decline in number, 3) lack of diversity, 4) imbalance, and 5) adverse consequences. The most common feature was not lack of diversity but extinction and decline in number.

"To what I knew, biodiversity loss is the extinction of some species due to the destruction that the human does to the natural environment. The destruction also results in the decline of species number. Currently, some species extinct, and some will be soon."

Interviewee 28 (34 years old, female, banker, Ho Chi Minh) 
Table 1: Perceptions of urban residents on biodiversity and biodiversity loss concepts

\begin{tabular}{|c|c|c|c|c|c|c|}
\hline & \multicolumn{3}{|c|}{ Biodiversity } & \multicolumn{3}{|c|}{ Biodiversity loss } \\
\hline & Category & \# & $\%$ & Category & \# & $\%$ \\
\hline \multirow{3}{*}{ Perceptions } & Goods in an ecosystem & 13 & $34.21 \%$ & $\begin{array}{l}\text { Loss of point of } \\
\text { equilibrium }\end{array}$ & 13 & $34.21 \%$ \\
\hline & An ecosystem itself & 12 & $31.58 \%$ & $\begin{array}{c}\text { Loss of goods in an } \\
\text { ecosystem }\end{array}$ & 11 & $28.95 \%$ \\
\hline & Stage of equilibrium & 4 & $10.53 \%$ & $\begin{array}{c}\text { Loss of stage of } \\
\text { ecosystem }\end{array}$ & 10 & $26.32 \%$ \\
\hline \multirow{5}{*}{ Features } & High diversity & 17 & $44.74 \%$ & Extinction & 16 & $42.11 \%$ \\
\hline & Plentifulness & 5 & $13.16 \%$ & Decline in number & 11 & $28.95 \%$ \\
\hline & $\begin{array}{l}\text { Clean and refreshing } \\
\text { context }\end{array}$ & 3 & $7.89 \%$ & Lack of diversity & 6 & $15.79 \%$ \\
\hline & Naturalness & 2 & $5.26 \%$ & Imbalance & 6 & $15.79 \%$ \\
\hline & $\begin{array}{l}\text { Existence of unique } \\
\text { objects/species }\end{array}$ & 2 & $5.26 \%$ & Adverse consequences & 5 & $13.16 \%$ \\
\hline
\end{tabular}

\subsection{Biodiversity (loss) impacts}

Table 2: Urban residents' perceived impacts of biodiversity and biodiversity loss on human

\begin{tabular}{|c|c|c|c|c|c|c|}
\hline & \multicolumn{2}{|c|}{ Impacts on the human } & \multicolumn{2}{c|}{ Impacts on the self } \\
\hline & Category & $\#$ & \% & Category & $\#$ & \% \\
\hline \multirow{4}{*}{ Benefits } & General impacts & 29 & $76.32 \%$ & Resources & 12 & $31.58 \%$ \\
\cline { 2 - 8 } & Resources & 21 & $55.26 \%$ & General impacts & 8 & $21.05 \%$ \\
\cline { 2 - 7 } & Health & 14 & $36.84 \%$ & Health & 7 & $18.42 \%$ \\
\cline { 2 - 7 } & Equilibrium & 12 & $31.58 \%$ & Recreation & 5 & $13.16 \%$ \\
\cline { 2 - 7 } & Recreation & 9 & $23.68 \%$ & Equilibrium & 1 & $2.63 \%$ \\
\hline
\end{tabular}

By asking the interviewees in two ways, we separated the perceived effect of biodiversity and biodiversity loss into two types: impact on humans in general and impact on the individual's self (see Table 2). In either type, the perceived effects could be classified into five categories: 1) general impacts, 2) resources (impacts associated with resource provision, such as food, medicines, products, etc.), 3) health (impact associated with human health, such as mental illness, well-being, animal attack, etc.), 4) equilibrium (impacts associated with perceived balance and harmony among human, other species, and the environment), and 5) recreation (impacts associated with recreational factors, such as nature-based tourism, natural scenery, etc.). The general impacts category refers to fresh air, natural disaster, biological life cycle, climate change, air pollution, water pollution, etc. Because these factors were hard to be differentiated and sometimes not scientifically inappropriate (e.g. natural disaster, pollutions, climate change), so we grouped them into one category and called them general impacts.Effects in this category were most frequently mentioned by the respondents $(76.32 \%)$. The second most commonly perceived effect category was resources, encompassing food, medicine, agricultural products, etc. 
"I think biodiversity is very important. If we do not conserve animals and plants well, our next generation will not be able to know extinct species. [...] Biodiversity loss has great impacts on the human's food and shelter due to floods, saltwater intrusion, and erosion. It also leads to air pollution, making residents less healthy."

Interviewee 24 (62 years old, male, officer, Ho Chi Minh)

"Trees provide humans with oxygen; animals provide humans with food. They help humans develop. However, we, humans, are exploiting nature too much. [...] For example, the extinction of species will make us lose the opportunity to watch their beauties, or we cannot eat extinct animals anymore."

Interviewee 19 (35 years old, female, seller, Ho Chi Minh)

Some residents knew that biodiversity and biodiversity loss had impacts on humans but could not describe what they were.

"Biodiversity is very important because an environment with high biological diversity is better than an environment without biological diversity. [...] If there is no biodiversity, the human's life will be affected, human development will not be natural."

Interviewee 20 (62 years old, male, officer, Ho Chi Minh)

We found that most respondents could report how biodiversity (loss) affects humanity (86.84\%). In contrast, $36.84 \%$ of respondents said that they did not know or there was no impact on themselves at all. Some even said that they did not care about the impact of biodiversity or biodiversity loss on their daily life.

"I think biodiversity does not affect me. Because even animal or plant species are exterminated or destroyed, it will not directly affect my living place and my life, so I don't really care. [...] Some effects might happen in the future, but there is nothing to worry now."

Interviewee 2 (21 years old, female, student, Hanoi) 


\subsection{Human's reaction towards biodiversity (loss)}

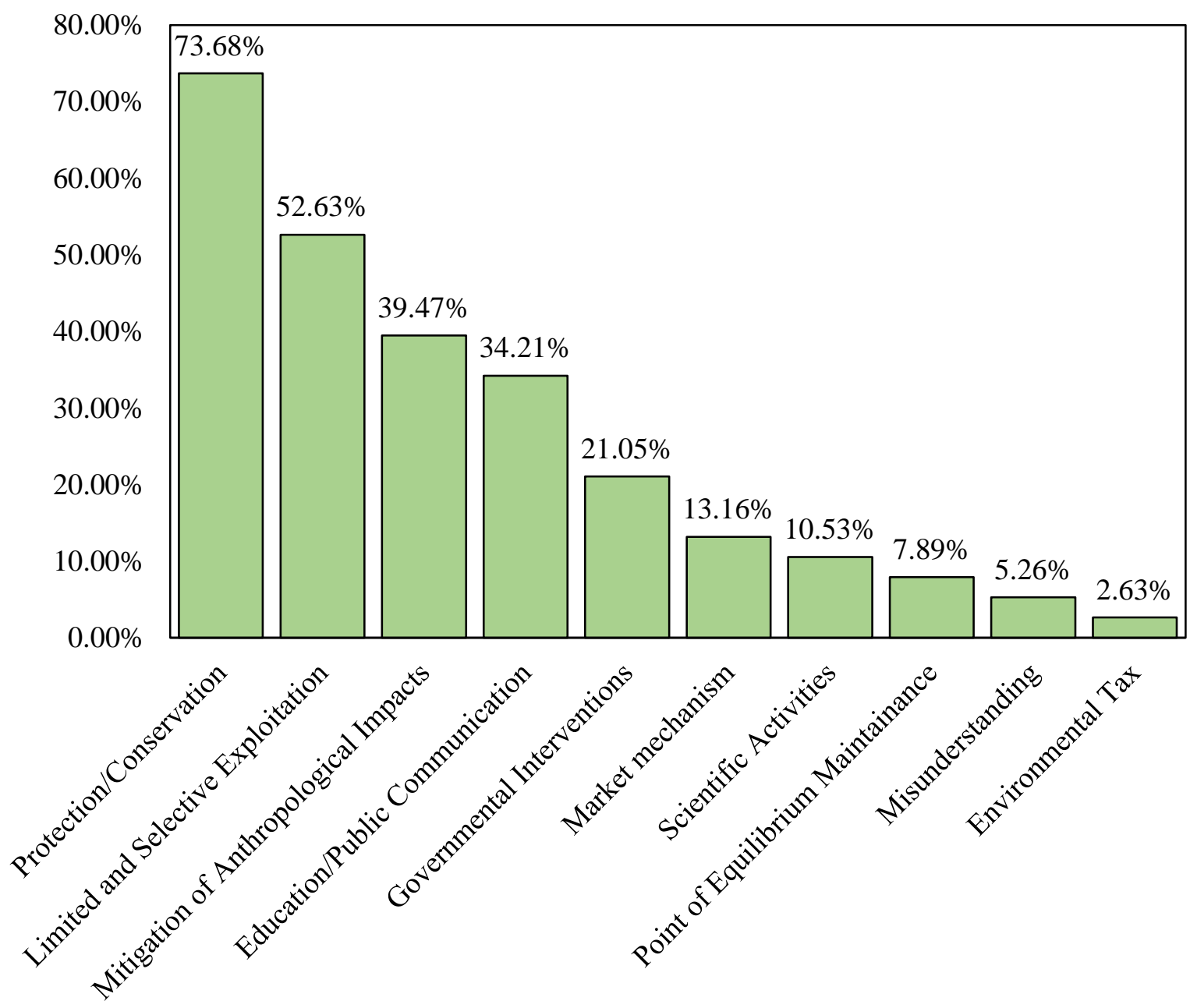

Figure 3: Urban residents' perceived measures of human to conserve biodiversity

This section reveals major categories of Vietnamese urban residents' perceived reaction to conserve biodiversity or halt biodiversity loss. We determined to combine both answers because the answers of how the interviewees and the human in general react were relatively mixed. Nine respondents $(23.68 \%)$ reported that they did not know whether residents around them and they could contribute to the conservation of biodiversity or prevention of biodiversity loss. Based on the analysis of the remaining responses, we categorized the reactions into ten different types following the descending order: 1) protection/conservation, 2) limited and selective exploitation, 3) mitigation of anthropological impacts, 4) education/public communication, 5) governmental interventions, 6) market mechanism, 7) scientific activities, 8) point of equilibrium maintenance, 9) misunderstanding, and 10) environmental tax (see Figure 3). Some example responses are displayed below:

"Protect the environment; stop illegal deforestation, stop wildife trading, stop littering plastic bottle or objects that are made from incombustible materials." 
Interviewee 17 (18 years old, female, student, Ho Chi Minh)

"We need to have a plan if we want to change something related to nature. The Vietnamese government has to implement more stringent regulations. For example, some mandatory environment-related criteria have to be met before constructing a building. Most of the land fund is currently used for construction without green space. Ocean and forest are being overexploited, and there is no natural conservation [...]. Everyone and I have to avoid using plastic products. [...] Endangered species have to be protected and conserved. There is a lot of marketing about the benefit and uniqueness of rhino horn, but I think that we cannot die without using the rhino horn, deer antler, or bear gall. They cannot help me live longer either."

Interviewee 13 (46 years old, female, businesswoman, Hanoi)

From the ten categories above, one significant finding emerges. The respondents were aware that biodiversity conservation and biodiversity loss prevention requires multi-stakeholders' participation: the public, the private sector, the academia, and the government. Environmental tax was also mentioned as a potential solution when the interviewee talked about policies and private sectors.

"First of all, the effort has to start from the residents's awareness, which can be changed quickly. If residents are getting more aware of protecting the forest, the environment, or even the surrounding living environment, they will be aware of protecting biodiversity. Besides residents's awareness, the government has to implement stricter policies and regulations. The scientists need to measure and evaluate the current situation of the environment for more appropriate exploitation, construction, and establishment of the special economic zone. Moreover, there needs to be a policy that requires residents to pay a certain amount of money for biodiversity conservation and improvement."

Interviewee 9 (24 years old, female, officer, Hanoi)

Sometimes, the respondents were over-optimistic about the role of genetic engineering in increasing biological diversity.

"On the one hand, the human needs to limit the exploitation. On the other hand, the human needs to create more animal and plant species with a mutated gene for increasing the biological diversity."

Interviewee 26 (20 years old, male, student, Ho Chi Minh) 


\section{Discussion}

This study is one of the first studies about the mental constructs of biodiversity and biodiversity loss among urban residents in southeast Asia. Previous studies were mainly conducted in developed Western countries, while this study was done in a developing Asian country - Vietnam. We performed Grounded Theory and semi-structured interviews on 38 residents in the two largest cities in Vietnam. After coding and analyzing the data, three main perceptions of the term 'biodiversity' and 'biodiversity loss' were found, along with their perceived features (see subsection 3.1). Moreover, we also identified five categories of perceived impacts of biodiversity (loss) on human (see subsection 3.2), and ten categories of perceived human's reaction that contributes to biodiversity conservation and biodiversity loss prevention (see subsection 3.3). Such findings were later used for questionnaire design [54].

Before discussing the main findings, we would like to address several limitations of the current study for transparency [55]. First of all, as a majority of samples in this study did not have sufficient knowledge about biology and ecology, their answers were relatively confusing and even illogical sometimes [56]. Thus, we had to rewrite and rearrange the structure of several unclear responses during the translation to improve the comprehension and coherence for later coding, analysis, and presentation in the manuscript. Although we tried our best to keep the interviewees' meaning unchanged during the translation and restructure, there was still the possibility that the presented results were not completely similar to the original answers. Furthermore, the qualitative analysis in this current study could not offer representative findings due to the low number of samples. Nevertheless, the current study's in-depth knowledge would lay a foundation for future studies related to urban residents's perceptions about biodiversity conservation and even the natural environment.

In either the perceptions of biodiversity or biodiversity loss, the equilibrium factor always appeared as a major category through typical expressions: 'balance', 'imbalance', 'harmony', 'peaceful', etc. It is clear that the notion of balance is frequently associated with biodiversity, even in the context of Western countries $[9,10,16,20]$. However, besides the knowledge and information that the interviewees knew about biodiversity (loss), we suspected that Vietnamese culture also had a certain influence on residents' perceptions. The cultural value was manifested through the expression of 'harmony' as a final goal of biodiversity (see subsection 3.1), which was not reported in former studies. Vietnamese residents are considerably affected by Confucianism, which has been embedded in their culture for many centuries [57,58]. Since the Confucian ideology emphasizes achieving harmony in society, it is plausible that the Vietnamese often associate good things, such as biodiversity, with harmony.

Comparably, findings from this study had both similarities and differences with prior research. Our results offered some consistent perceived features of biodiversity with the study of Fischer and Young [9], like naturalness, plentifulness, and high diversity. The interview responses in our study were not as detailed as those in Fischer and Young [9]'s study because urban residents do not have many chances to interact with the natural environment. Still, we could identify two new biodiversity features perceived by urban residents: clean and refreshing context and existence of unique objects/species. Bakhtiari, Jacobsen, Strange and Helles [10] suggested two types of forest 
biodiversity definitions: biodiversity as a good in itself and biodiversity as a regulator of the ecosystem. Only one of the three interviewees' perceptions (goods in an ecosystem) in our study was consistent with Bakhtiari, Jacobsen, Strange and Helles [10]'s suggestion. Instead of considering biodiversity a regulator in an ecosystem, Vietnamese urban residents genuinely perceived biodiversity as an ecosystem itself or a stage of equilibrium.

Apparently, these answers were not correct in the sense of science. Still, they were plausible results because of five reasons: 1) a significant number of respondents have never heard of the term 'biodiversity' $(36.84 \%)$ or 'biodiversity loss' $(52.63 \%)$; 2) a majority of urban residents have limited experience with the natural environment; 3) environmental education is not focal in Vietnamese education curriculum [59]; 4) the definition of biodiversity is complex and sometimes ambiguous, even among conservationists and ecologists [14]; 5) the term 'biology' [sinh học] is relatively similar to the term 'ecology' [sinh thái] in Vietnamese, which might cause confusion among layresidents.

Also, because of the five reasons mentioned above, Vietnamese urban residents might have low awareness of biodiversity loss impacts on their lives and obtain some scientifically inaccurate perceptions about the utility of genetic engineering techniques. Some residents were overoptimistic about the utility of genetic engineering in raising biodiversity without knowing the existing adverse effects of genetically modified species on the biodiversity and ecosystem. Even though genetic engineering has some benefits in biodiversity conservation practices, it can create devastating consequences without stringent monitoring [60].

We recommend that policymakers should focus on education and public communication activities about environmental issues, especially biodiversity. Sufficient education and public communication about biodiversity impact on the human would facilitate the conservation effort and decelerate the biodiversity loss rate in Vietnam [28,30,34,35]. As shown in this study that some residents were aware of the significance of multi-stakeholders' participation in solving biodiversity loss, promoting cooperation projects, programs, and campaigns among government, private sectors, researchers, and the public is a potential approach for effectively conserving biodiversity. The first step could be accomplishing the $11^{\text {th }}$ progressive cultural value - the environment-healing element or eco-surplus culture [61,62], which supplements to Harrison [63]'s list of ten values. For aiding evidence-based policy-making, quantitative studies with larger and more representative samples have to be conducted. Moreover, the associations between urban residents' biodiversity perceptions and their willingness to pay for conservation programs, attitudes towards wildlife trading, and nature-based tourism behaviors need to be further explored. 


\section{Acknowledgements}

We would like to send our gratitude to my family and friends for supporting me during the research, especially Prof. Vuong Quan Hoang (Phenikaa University) and Mr. Le Tam Tri (Phenikaa University).

\section{Funding}

Not applicable

\section{Conflicts of interest}

This study is a part of the author's dissertation (M.-H.N).

\section{Data availability}

The data that supports the findings of this study is available from the authors upon reasonable request.

\section{Code availability}

Not applicable

\section{CRediT author statement}

Conceptualization: Minh-Hoang Nguyen; Methodology: Minh-Hoang Nguyen; Formal analysis and investigation: Minh-Hoang Nguyen; Writing - original draft preparation: Minh-Hoang Nguyen, Thomas E. Jones; Writing - review and editing: Minh-Hoang Nguyen, Thomas E. Jones; Validation: Thomas E. Jones; Resources: Minh-Hoang Nguyen; Supervision: Thomas E. Jones

\section{References}

1. World Wildlife Fund. Living Planet Report 2020 - Bending the curve of biodiversity loss; Gland, Switzerland, 2020. 
2. Intergovernmental Science-Policy Platform on Biodiversity and Ecosystem Services. Nature's Dangerous Decline 'Unprecedented' Species Extinction Rates 'Accelerating'. Available online: https://www.unenvironment.org/news-and-stories/press-release/natures-dangerous-declineunprecedented-species-extinction-rates (accessed on 24/06).

3. Lambers, J.H.R. Extinction risks from climate change. Science 2015, 348, 501-502.

4. Giam, X. Global biodiversity loss from tropical deforestation. Proceedings of the National Academy of Sciences 2017, 114, 5775-5777.

5. Doherty, T.S.; Glen, A.S.; Nimmo, D.G.; Ritchie, E.G.; Dickman, C.R. Invasive predators and global biodiversity loss. Proceedings of the National Academy of Sciences 2016, 113, 11261-11265.

6. Marques, A.; Martins, I.S.; Kastner, T.; Plutzar, C.; Theurl, M.C.; Eisenmenger, N.; Huijbregts, M.A.; Wood, R.; Stadler, K.; Bruckner, M. Increasing impacts of land use on biodiversity and carbon sequestration driven by population and economic growth. Nature Ecology \& Evolution 2019, 3, 628-637.

7. Eneji, V.; Gubo, Q.; Okpiliya, F.; Aniah, E.; Eni, D.; Afangide, D. Problems of public participation in biodiversity conservation: the Nigerian scenario. Impact Assessment and Project Appraisal 2009, 27, 301-307.

8. Kaltenborn, B.P.; Gundersen, V.; Stange, E.; Hagen, D.; Skogen, K. Public perceptions of biodiversity in Norway: From recognition to stewardship? Norsk Geografisk Tidsskrift-Norwegian Journal of Geography 2016, 70, 54-61.

9. Fischer, A.; Young, J.C.J.B.c. Understanding mental constructs of biodiversity: implications for biodiversity management and conservation. 2007, 136, 271-282.

10. Bakhtiari, F.; Jacobsen, J.B.; Strange, N.; Helles, F. Revealing lay people's perceptions of forest biodiversity value components and their application in valuation method. Global Ecology Conservation 2014, 1, 27-42.

11. Hunter, L.M.; Brehm, J. Qualitative insight into public knowledge of, and concern with, biodiversity. Human Ecology 2003, 309-320.

12. Faith, D.P. Biodiversity. Available online: https://plato.stanford.edu/entries/biodiversity/\#WhatDoWeMeanVariDiveHowDoWeMeaslt (accessed on

13. Ehrenfeld, D. Why put a value on biodiversity? In Biodiversity, Wilson, E., FM, P., Eds.; National Academies Press: Washington, 1988.

14. Mace, G.M.; Norris, K.; Fitter, A.H. Biodiversity and ecosystem services: a multilayered relationship. Trends in Ecology \& Evolution 2012, 27, 19-26.

15. Convention on Biological Diversity. Article 2. Use of Terms. Available online: https://www.cbd.int/convention/articles/?a=cbd-02 (accessed on

16. Buijs, A.E.; Fischer, A.; Rink, D.; Young, J.C. Looking beyond superficial knowledge gaps: Understanding public representations of biodiversity. The International Journal of Biodiversity Science \& Management 2008, 4, 65-80.

17. Nisiforou, O.; Charalambides, A.G. Assessing undergraduate university students' level of knowledge, attitudes and behaviour towards biodiversity: a case study in Cyprus. International Journal of Science Education 2012, 34, 1027-1051.

18. Şekercioğlu, Ç.H. Promoting community-based bird monitoring in the tropics: Conservation, research, environmental education, capacity-building, and local incomes. Biological Conservation 2012, 151, 69-73.

19. Tonin, S.; Lucaroni, G. Understanding social knowledge, attitudes and perceptions towards marine biodiversity: The case of tegnùe in Italy. Ocean \& Coastal Management 2017, 140, 68-78. 
20. Dandy, N.; Ballantyne, S.; Moseley, D.; Gill, R.; Quine, C.; Van Der Wal, R. Exploring beliefs behind support for and opposition to wildlife management methods: a qualitative study.

European Journal of Wildlife Research 2012, 58, 695-706.

21. Muratet, A.; Pellegrini, P.; Dufour, A.-B.; Arrif, T.; Chiron, F. Perception and knowledge of plant diversity among urban park users. Landscape Urban Planning 2015, 137, 95-106.

22. Kelemen, E.; Nguyen, G.; Gomiero, T.; Kovács, E.; Choisis, J.-P.; Choisis, N.; Paoletti, M.G.; Podmaniczky, L.; Ryschawy, J.; Sarthou, J.-P. Farmers' perceptions of biodiversity: lessons from a discourse-based deliberative valuation study. Land Use Policy 2013, 35, 318-328.

23. Vuong, Q.-H.; Napier, N.K. Acculturation and global mindsponge: an emerging market perspective. International Journal of Intercultural Relations 2015, 49, 354-367.

24. Vuong, Q.-H. Global mindset as the integration of emerging socio-cultural values through mindsponge processes: A transition economy perspective. In Global Mindsets, Kuada, J., Ed.; Routledge: 2016; pp. 123-140.

25. Nguyen, M.-H.; Le, T.-T.; Ho, M.-T.; Nguyen, H.T.T.; Vuong, Q.-H. Alice in Suicideland: Exploring the Suicidal Ideation Mechanism through the Sense of Connectedness and Help-Seeking Behaviors. IJERPH 2021, 18, 3681, doi:https://doi.org/10.3390/ijerph18073681.

26. Christie, M.; Fazey, I.; Cooper, R.; Hyde, T.; Kenter, J.O. An evaluation of monetary and nonmonetary techniques for assessing the importance of biodiversity and ecosystem services to people in countries with developing economies. Ecological Economics 2012, 83, 67-78.

27. Scheffers, B.R.; Oliveira, B.F.; Lamb, I.; Edwards, D.P. Global wildlife trade across the tree of life. Science 2019, 366, 71-76.

28. Nuwer, R.L. Poached: inside the dark world of wildlife trafficking; Da Capo Press: New York, 2018.

29. Ministry of Natural Resources and Development. Vietnam's fifth national report to the United Nations Convention on Biological Diversity; Hanoi, 2014.

30. Wyler, L.S.; Sheikh, P.A. International illegal trade in wildlife: Threats and U.S. policy; Congressional Research Service: Washington, 2013.

31. Challender, D.W.; Harrop, S.R.; MacMillan, D.C. Understanding markets to conserve tradethreatened species in CITES. Biological Conservation 2015, 187, 249-259.

32. Zhang, L.; Yin, F. Wildlife consumption and conservation awareness in China: a long way to go. Biodiversity and Conservation 2014, 23, 2371-2381.

33. Clark, N.E.; Lovell, R.; Wheeler, B.W.; Higgins, S.L.; Depledge, M.H.; Norris, K. Biodiversity, cultural pathways, and human health: a framework. Trends in Ecology Evolution 2014, 29, 198 204.

34. Tapper, R. Wildlife watching and tourism: a study on the benefits and risks of a fast growing tourism activity and its impacts on species; UNEP/Earthprint: 2006.

35. Chung, M.G.; Dietz, T.; Liu, J. Global relationships between biodiversity and nature-based tourism in protected areas. Ecosystem Services 2018, 34, 11-23.

36. Balmford, A.; Beresford, J.; Green, J.; Naidoo, R.; Walpole, M.; Manica, A. A global perspective on trends in nature-based tourism. PLoS biology 2009, 7.

37. Khai, H.V.; Yabe, M. The demand of urban residents for the biodiversity conservation in $U$ Minh Thuong National Park, Vietnam. Agricultural and Food Economics 2014, 2, 10.

38. Fredman, P.; Tyrväinen, L. Frontiers in nature - based tourism. Scandinavian Journal of Hospitality and Tourism 2010, 10, 177-189.

39. Karanth, K.K.; DeFries, R. Nature - based tourism in Indian protected areas: New challenges for park management. Conservation Letters 2011, 4, 137-149. 
40. Lundmark, L.; Müller, D.K. The supply of nature-based tourism activities in Sweden. Tourism: An International Interdisciplinary Journal 2010, 58, 379-393.

41. Fuller, R.A.; Irvine, K.N.; Devine-Wright, P.; Warren, P.H.; Gaston, K.J. Psychological benefits of greenspace increase with biodiversity. Biology Letters 2007, 3, 390-394.

42. Fuller, R.A.; Irvine, K.N. Interactions between people and nature in urban environments. In Urban Ecology, Gaston, K.J., Ed.; Cambridge University Press: Cambridge 2010; pp. 134-171.

43. Shwartz, A.; Turbé, A.; Simon, L.; Julliard, R. Enhancing urban biodiversity and its influence on city-dwellers: An experiment. Biological Conservation 2014, 171, 82-90.

44. Chun Tie, Y.; Birks, M.; Francis, K. Grounded theory research: A design framework for novice researchers. SAGE Open Medicine 2019, 7, 2050312118822927.

45. Glaser, B.G.; Strauss, A.L. Awareness of dying; Aldine: Chicago, 1965.

46. Glaser, B.G.; Strauss, A.L. The discovery of grounded theory : strategies for qualitative research; Aldine: Chicago, 1967.

47. Ralph, N.; Birks, M.; Chapman, Y. The methodological dynamism of grounded theory. International Journal of Qualitative Methods 2015, 14, 1609406915611576.

48. General Statistics Office. Area, population and population density by province by cities, provincies, year and items. 2020.

49. Horton, J.; Macve, R.; Struyven, G. Qualitative research: experiences in using semi-structured interviews. In The real life guide to accounting research: $A$ behind-the-scenes view of using qualitative research methods, Humphrey, C., Lee, B., Eds.; Elsevier: Amsterdam, Boston 2004; pp. 339-357.

50. Whiting, L.S. Semi-structured interviews: Guidance for novice researchers. Nursing Standard 2008, 22.

51. Creswell, J.W.; Poth, C.N. Qualitative inquiry and research design : choosing among five approaches; SAGE: Los Angeles, 2018.

52. Abfalter, D.; Mueller-Seeger, J.; Raich, M. Translation decisions in qualitative research: a systematic framework. International Journal of Social Research Methodology 2020, 1-18.

53. Birks, M.; Mills, J. Grounded theory: a practical guide, 2nd ed.; SAGE: London, 2015.

54. Nguyen, M.-H. Multifaceted interactions between urban humans and biodiversity-related concepts: A developing-country dataset. Data Intelligence 2021, 3, 578-605.

55. Vuong, Q.-H. Reform retractions to make them more transparent. Nature 2020, 582, 149, doi:10.1038/d41586-020-01694-x.

56. Temple, B.; Young, A. Qualitative research and translation dilemmas. Qualitative Research 2004, 4, 161-178.

57. Vuong, Q.-H.; Bui, Q.-K.; La, V.-P.; Vuong, T.-T.; Nguyen, V.-H.T.; Ho, M.-T.; Nguyen, H.-K.T.; Ho, M.-T. Cultural additivity: behavioural insights from the interaction of Confucianism, Buddhism and Taoism in folktales. Palgrave Communications 2018, 4, 143, doi:10.1057/s41599-018-01892.

58. Vuong, Q.-H.; Ho, M.-T.; Nguyen, H.-K.T.; Vuong, T.-T.; Tran, T.; Hoang, K.-L.; Vu, T.-H.; Hoang, P.H.; Nguyen, M.-H.; Ho, M.-T.; et al. On how religions could accidentally incite lies and violence: folktales as a cultural transmitter. Palgrave Communications 2020, 6, 82, doi:10.1057/s41599020-0442-3.

59. Heck, E.H. Environmental education in Vietnam: A case study at Le Loi elementary school. Independent Study Project (ISP) Collection 2015, 2223.

60. Landry, H. Challenging evolution: How GMOs can influence genetic diversity. Available online: https://sitn.hms.harvard.edu/flash/2015/challenging-evolution-how-gmos-can-influencegenetic-diversity/ (accessed on 27 May). 
61. Vuong, Q.H. The semiconducting principle of monetary and environmental values exchange. Economics and Business Letters 2021, 10, 284-290, doi:10.17811/ebl.10.3.2021.284-290.

62. Vuong, Q.-H. Western monopoly of climate science is creating an eco-deficit culture. Economy, Land \& Climate Insight 2021. Available online: https://elc-insight.org/western-monopoly-ofclimate-science-is-creating-an-eco-deficit-culture/

63. Harrison, L.E. Culture matters. The National Interest 2000, 60, 55-65. 